\title{
Numerical Study of the Solar Chimney Power Plant Performance in the Region of M'Sila-Algeria
}

\author{
Samir Djimli ${ }^{1}$, Abla Chaker ${ }^{2}$ \\ ${ }^{1,2}$ Energy Physics Laboratory \\ Department of physics \\ University of Mentouri Constantine 1 (Algeria) \\ Phone/Fax number: +0021331841559, e-mail: djsamir.25@gmail.com,chakamine@yahoo.fr
}

\begin{abstract}
This work offers the opportunity to examine the possibility of implementing a solar chimney power plant in the region of M'Sila (Algeria) whose solar potential is exceptional. The solar chimney is a generator of electricity starting from solar energy. Performance analysis of a solar chimney which has similar characteristics to prototype Manzaneres (Spain), that could produce $39-72 \mathrm{~kW}$, and that would be used to supply electricity to 39000 - 72000 inhabitants, was performed using the software fluent. The results obtained are very promising.
\end{abstract}

\section{Key words}

Renewable Energy, Solar energy, solar chimney/tower, solar collector

\section{Introduction}

The rapid increases in population and economic development have led to a growing demand for energy. The unavoidable exhaustion of fossil fuels along with their more polluting forces changes the direction of efforts and research into renewable sources.

Solar energy is one of the great hopes of mankind. Many applications of this inexhaustible and proenvironmental source are known. Among them is the solar chimney used to produce electrical energy from sunlight.

This generator electrical power, introduced by Professor J.Schlaich Stuttgart in 1968 [1], consists of three main components: the solar collector (called also the greenhouse), the chimney (the tower) and, the wind turbine.

The heated air in the collector (open to the periphery to introduce fresh air) rises above a fireplace located in the center of the collector. A wind turbine in the base of the chimney is placed in the trajectory of the air-flow to convert the kinetic energy thereof into mechanical energy. The generator brought about by the turbine converts mechanical energy into electrical energy.
The prototype of Manzanares in Spain is the only solar chimney of industrial scale in the world that was built and tested over the years 1982-1989. Many other projects were announced in different countries (India, Australia, China, Namibia, USA, Chile ...), but none has emerged.

This work examines the possibility of implementing a solar chimney power plant in the region of M'Sila (Algeria), in which the solar potential is exceptional. Our main focus is on the performance of such a facility.

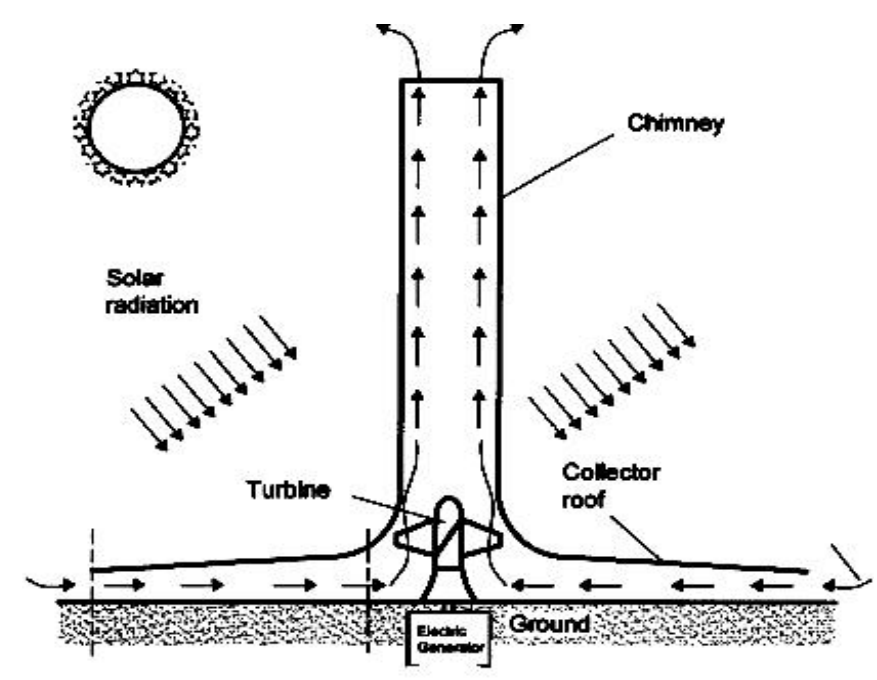

Fig. 1. Solar chimney 


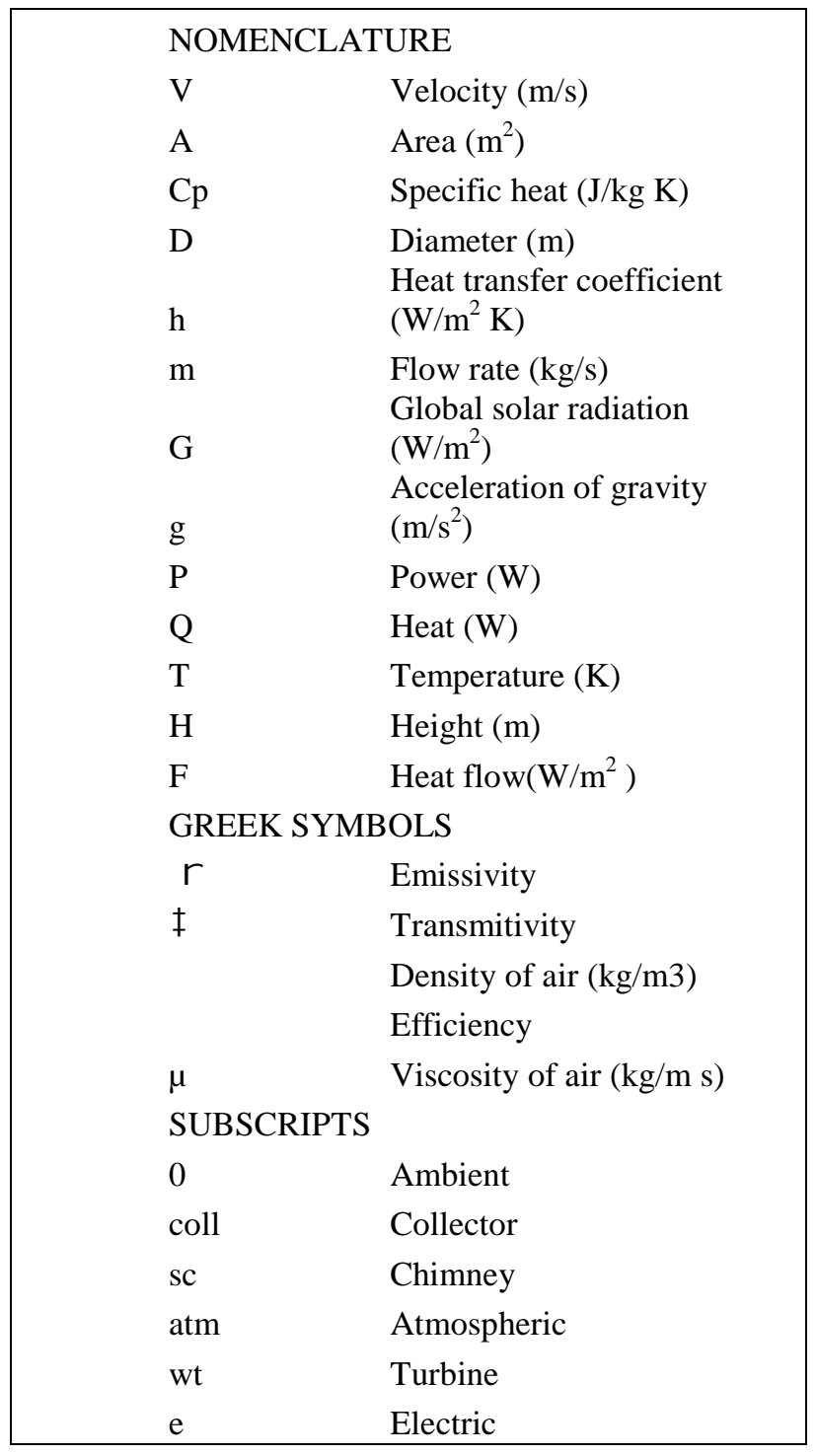

\section{Mathematical Model And Boundary Conditions}

The geometry of the solar chimney, which is illustrated in fig 2, consists of two cylindrical cavities. They are open and superimposed on each other (the chimney and collectors). The characteristics of the rotational symmetry of the cylinder makes the solution twodimensional (depends only on $\mathrm{r}$ and $\mathrm{z}$ ).

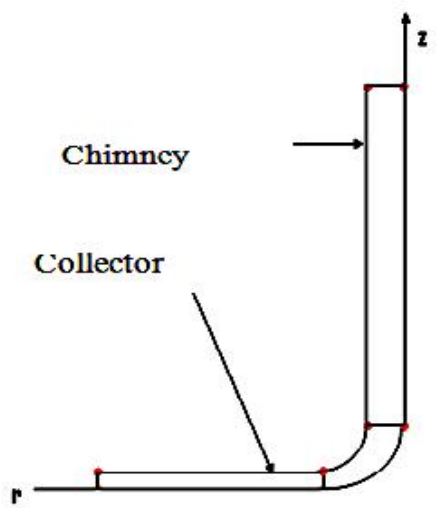

Fig. 2. Two-dimensional geometric of the solar chimney
The equations that describe the flow in cylindrical coordinates are given by [2]:

Mass conservation:

$\frac{\partial \rho}{\partial t}+\frac{u}{r}+\frac{\partial u}{\partial r}+\frac{\partial v}{\partial z}=0$

Linear r-momentum conservation:

$\frac{\partial(\rho u)}{\partial t}+u \frac{\partial u}{\partial r}+v \frac{\partial u}{\partial z}=\frac{\mu}{\rho}\left(\frac{u}{r^{2}}+\nabla^{2} u\right)+\frac{-1}{\rho} \frac{\partial p}{\partial r}$

Linear z-momentum conservation:

$\frac{\partial(\rho v)}{\partial t}+\frac{\partial v}{\partial r}+v \frac{\partial v}{\partial z}=\frac{\mu}{\rho} \nabla^{2} v+\frac{-1}{\rho} \frac{\partial p}{\partial z}-\frac{\rho_{T}}{\rho} g$

Energy conservation:

$\frac{\partial(\rho T)}{\partial t}+u \frac{\partial T}{\partial r}+v \frac{\partial T}{\partial z}=\alpha \nabla^{2} T$

The model of turbulence used is $k-\varepsilon$. Equation of turbulent kinetic energy $k$ :

$\frac{\partial k}{\partial t}+\bar{u}_{k} \frac{\partial k}{\partial x_{k}}=\frac{\partial}{\partial x_{k}}\left[\left(v+\frac{C_{u} k^{2}}{\sigma_{k} \varepsilon}\right) \frac{\partial k}{\partial x_{k}}\right]$

$+\frac{C_{u} k^{2}}{\varepsilon}\left(\frac{\partial \bar{u} i}{\partial x_{k}}+\frac{\partial \bar{u}_{k}}{\partial x_{i}}\right) \frac{\partial \bar{u}_{i}}{\partial x_{k}}-\varepsilon$

Equation of the dissipation of the turbulent kinetic energy $\varepsilon$ :

$\frac{\partial \varepsilon}{\partial t}+\bar{u}_{k} \frac{\partial \varepsilon}{\partial x_{k}}=\frac{\partial}{\partial x_{k}}\left(v+\frac{C_{u} k^{2}}{\sigma_{e} \varepsilon}\right) \frac{\partial \varepsilon}{\partial x_{k}}$

$+C_{\varepsilon 1} C_{u} k\left(\frac{\partial \bar{u}_{i}}{\partial x_{k}}+\frac{\partial \bar{u}_{k}}{\partial x_{i}}\right) \frac{\partial \bar{u}_{i}}{\partial x_{k}}-C_{\varepsilon 2} \frac{\varepsilon^{2}}{k}$

Constants take the following values [3]:

$C_{1 \varepsilon}=1.44, C_{2 \varepsilon}=1.92, C_{\mu}=0.09, \sigma_{k}=1.0, \sigma_{\varepsilon}=1.3$

\section{A. Solar collector}

The efficiency of collector is given by:

$\eta_{\text {coll }}=\frac{\dot{Q}}{A_{\text {coll }} \cdot G}$

The heat generated $\dot{Q}$ and mass flow $\dot{m}$ are respectively given by equations 8 and 9

$\dot{Q}=\dot{m} \cdot C_{p} \cdot \Delta T$

$\dot{m}=\rho_{\text {coll }} \cdot V_{c} \cdot A_{c}$ 
By substituting in Equation 7, $\dot{Q}$ and $\dot{m}$ by their expressions, we obtain the relation:

$\eta_{\text {coll }}=\frac{\rho_{\text {coll }} \cdot V_{c} \cdot A_{c} \cdot C_{p} \cdot \Delta T}{A_{\text {coll }} \cdot G}$

\section{B. solar chimney}

The efficiency of the chimney is expressed by [4]:

$\eta_{s c}=\frac{P_{t o t}}{\dot{Q}}=\frac{g H_{s c}}{C_{p} T_{0}}$

The pressure difference produced by the chimney is calculated by:

$$
\Delta P_{\text {tot }}=\rho_{\text {coll }} g H_{s c} \frac{\Delta T}{T_{0}}
$$

The electrical power is given by:

$$
P_{e}=\frac{2}{3} \eta_{\text {coll }} \eta_{w t} \frac{g}{C_{p} T_{0}} H_{s c} A_{c o l l} G
$$

Where $\eta_{w t}$ is the turbine efficiency.

The boundary conditions and the parameters used in the calculations are recorded in Tables I and II

Table I. Boundary conditions

\begin{tabular}{|l|l|l|}
\hline Place & Type & Value \\
\hline Bottom of the collector & Heat flow & $\mathrm{F}\left(\mathrm{W} / \mathrm{m}^{2} \mathrm{~K}\right)$ \\
\hline Top of the collector & Wall & $\mathrm{T} 0, \mathrm{~h}=10 \mathrm{~W} / \mathrm{m}^{2} \mathrm{~K}$ \\
\hline Surface of the chimney & Wall & $\mathrm{qsc}=0 \mathrm{~W} / \mathrm{m}^{2} \mathrm{~K}$ \\
\hline Collector inlet & Pressure inlet & $\mathrm{P}=$ Patm, T=T0 \\
\hline Chimney outlet & Pressure outlet & $\mathrm{P}=$ Patm \\
\hline
\end{tabular}

Table II - Dimensions and parameters used

\begin{tabular}{|l|c|l|c|}
\hline \multicolumn{1}{|c|}{ Parameters } & Value & Parameters & Value \\
\hline Chimney height $\left(\mathrm{H}_{\mathrm{sc}}\right)$ & $194,6 \mathrm{~m}$ & $\begin{array}{l}\text { Product of } \\
\text { transmittance and } \\
\text { absorbance of the } \\
\text { collector } \alpha \tau\end{array}$ & 0,65 \\
\hline Chimney diameter $\left(\mathrm{D}_{\mathrm{sc}}\right)$ & $10 \mathrm{~m}$ & $244 \mathrm{~m}$ \\
\hline $\begin{array}{c}\text { Distance from ground to } \\
\text { the cover }\left(\mathrm{H}_{\text {coll }}\right)\end{array}$ & $\begin{array}{c}1,85-3,7 \\
\mathrm{~m}\end{array}$ & $\begin{array}{l}\text { Collector } \\
\text { diameter }\left(\mathrm{D}_{\text {coll }}\right)\end{array}$ & \\
\cline { 1 - 3 }$\eta_{w t}$ & 0,85 & Efficiency of the turbine & \\
\hline
\end{tabular}

\section{Results and Discussion}

The performance of any solar system is closely related to solar irradiation. Our interest examined first of all this key parameter. The evolution of annual solar irradiation of the regions of M'Sila (Algeria) and Manzanares (Spain) in which the only prototype solar chimney of industrial scale has been achieved is shown in figure 3 .

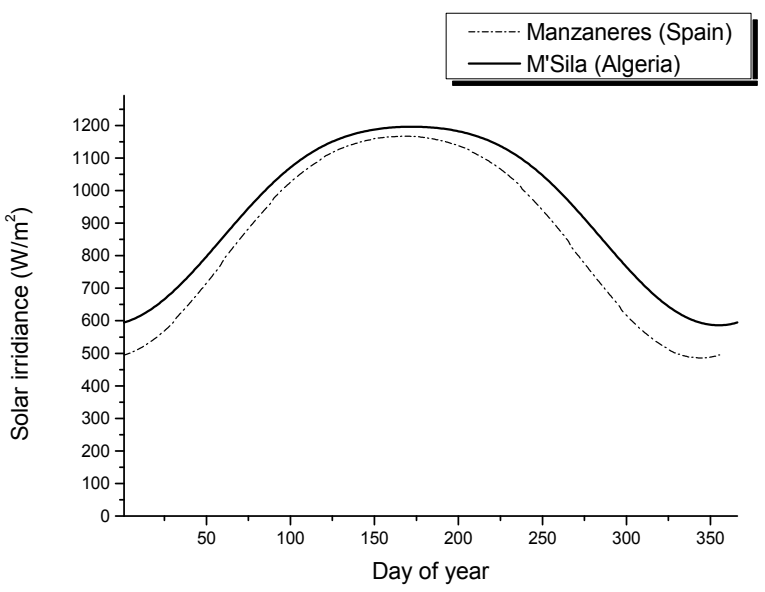

Fig. 3. Variation of solar radiation for the two regions during the years

We can notice that the two curves have a similar shape $[5,6]$. However, because of their geographical positions the solar potential of the region of M'Sila is higher than that of Manzanares.

Also, it may be noticed that the maximum value of solar irradiation for the region of M'Sila in the range of $1197 \mathrm{w} / \mathrm{m}^{2}$ fits with day 171 of the year

The examination of the curves of figure 4 , indicating the monthly variations in solar radiation and ambient temperature, helps us to observe that the solar radiation varies approximately through the year from $600 \mathrm{~W} / \mathrm{m}^{2}$ to $1200 \mathrm{~W} / \mathrm{m}^{2}$.

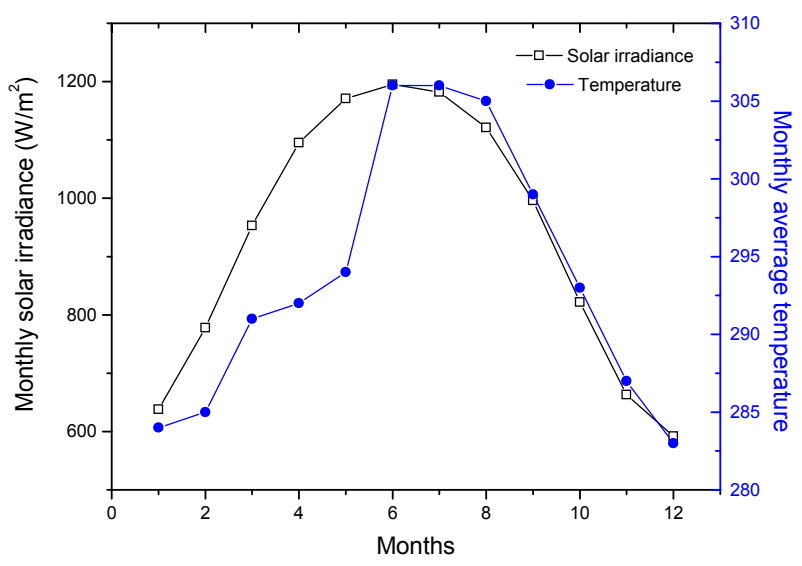

Fig. 4. Average monthly solar radiation and ambient temperature 
The temperature profile through the collector (from input to output) for 4 months of the year (January, April, July and October) is illustrated by the curves of Figure 5. It seems that the variation is almost linear for all 4 months [7,8]. Furthermore, it is noticed that the increase in temperature ranges from $22-30^{\circ} \mathrm{C}$.

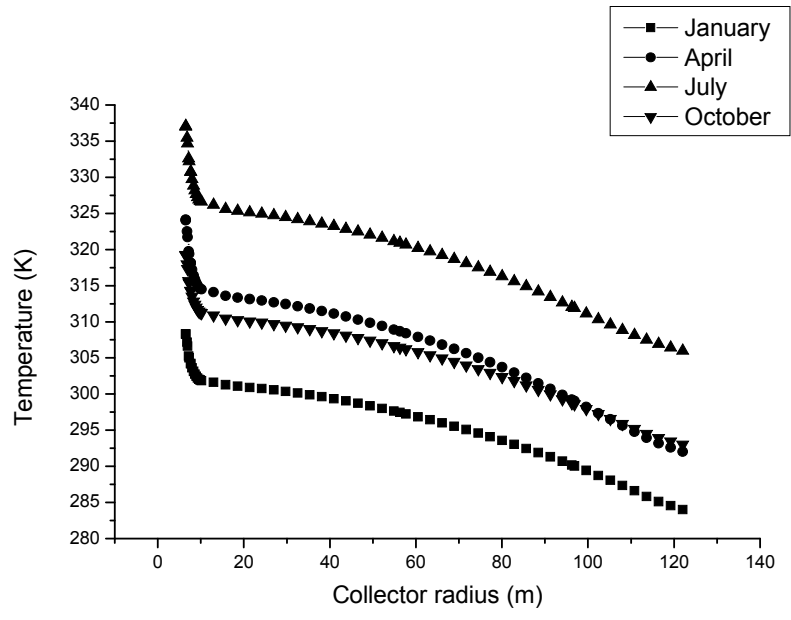

Fig. 5. Air temperature through the collector

It is easy to observe that the curve representing the monthly change in the production of electrical energy (Figure 6) has a similar appearance to that of the solar radiation. In addition, we can notice that this production varies during the year from 35 to $72 \mathrm{KW}$.

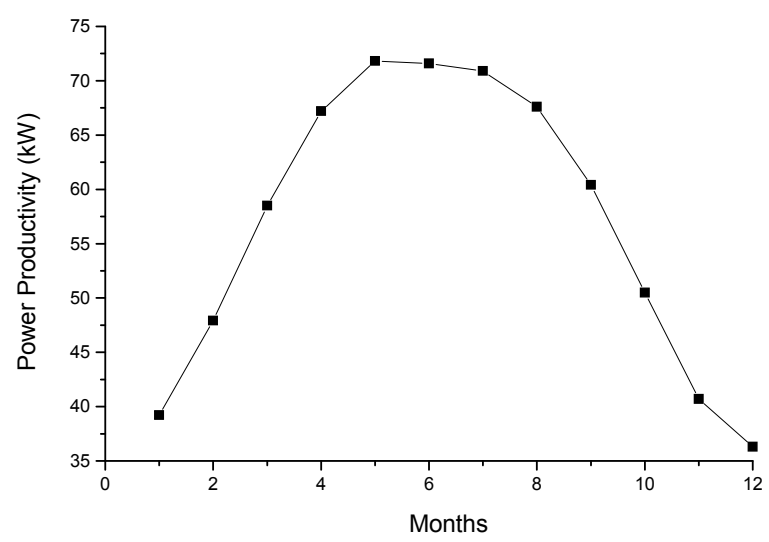

Fig. 6. Average monthly power productivity

In order to deepen our investigation on the site of M'Sila, the evolution of solar radiation on the 21 st day of the months of the year (January, April, July and October) is shown in Figures 7-10.

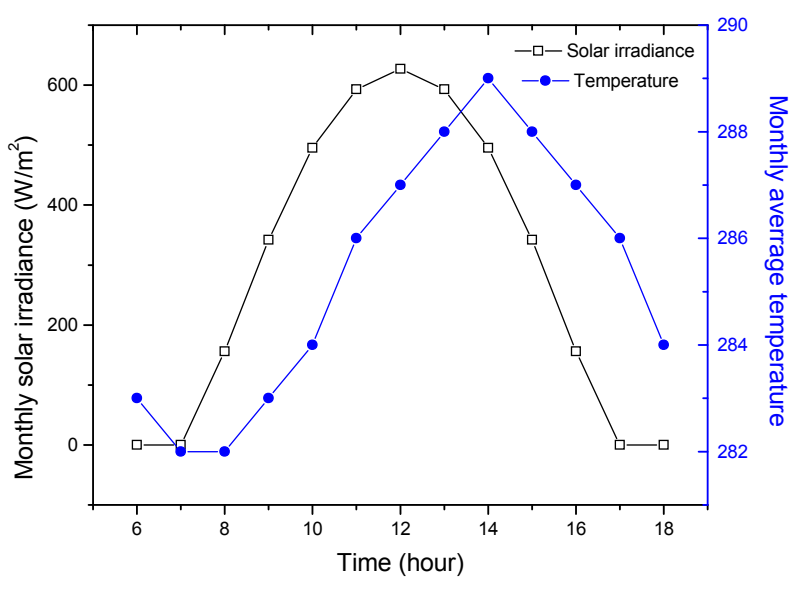

Fig. 7. Variation of solar radiation and ambient temperature versus time of January 21

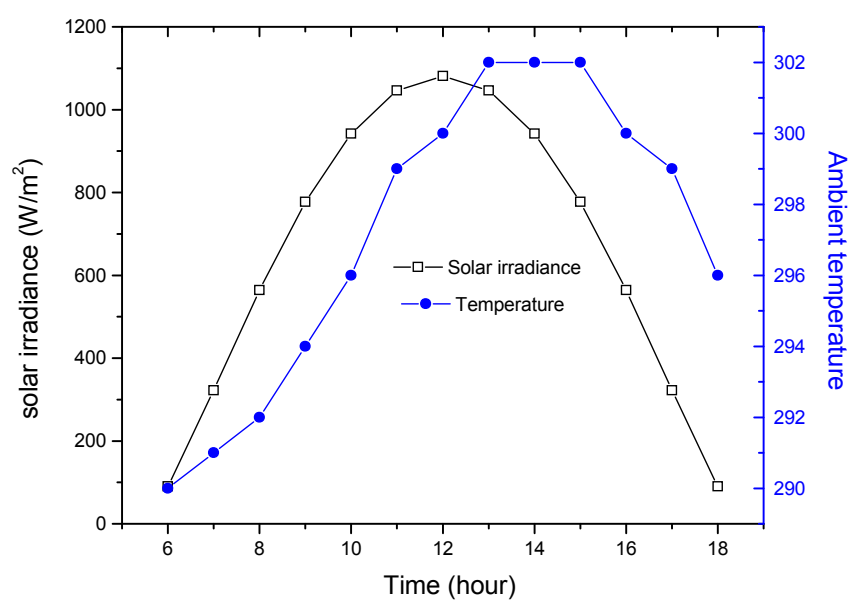

Fig. 8. Variation of solar radiation and ambient temperature versus time of April 21

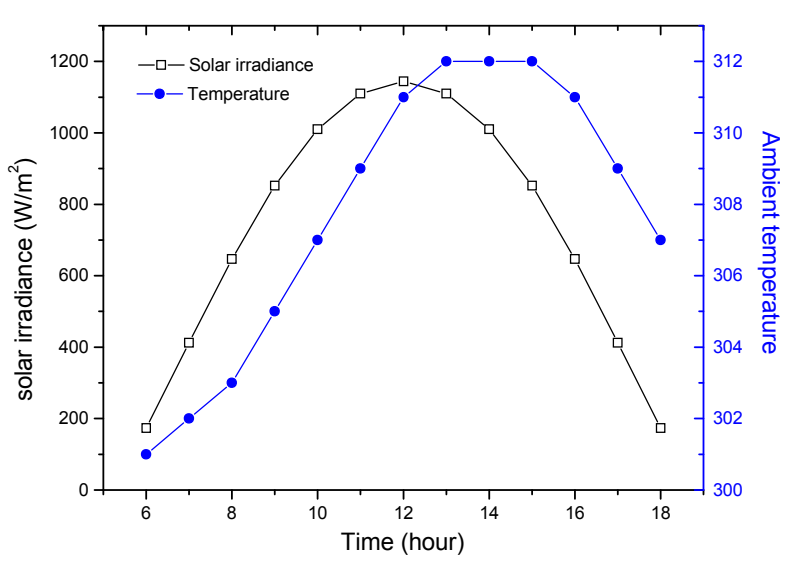

Fig. 9. Variation of solar radiation and ambient temperature versus time of July 21 


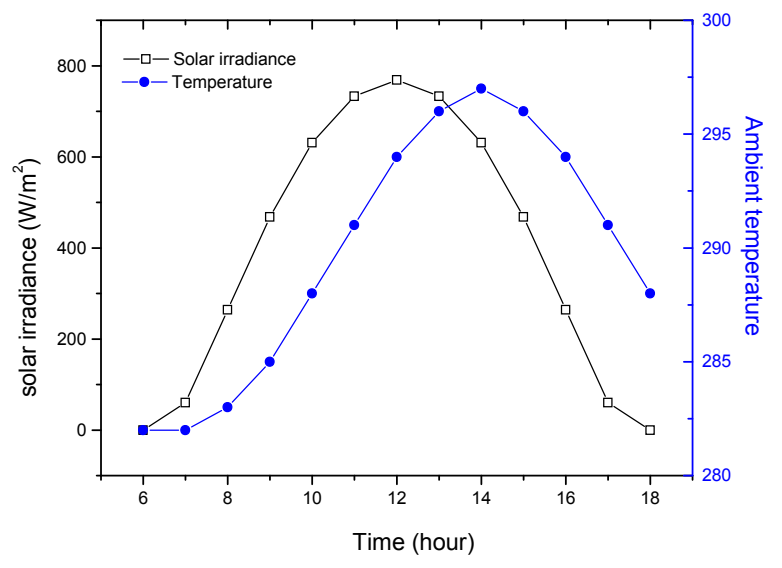

Fig. 10. Variation of solar radiation and ambient temperature versus time of October 21

The curves in Figures 7-10 show that the maximum solar irradiation is observed between 11 a.m and 01p.m for all 4 days. On the other hand, the highest value, of the order of $1200 \mathrm{~W} / \mathrm{m}^{2}$, is reached in July.

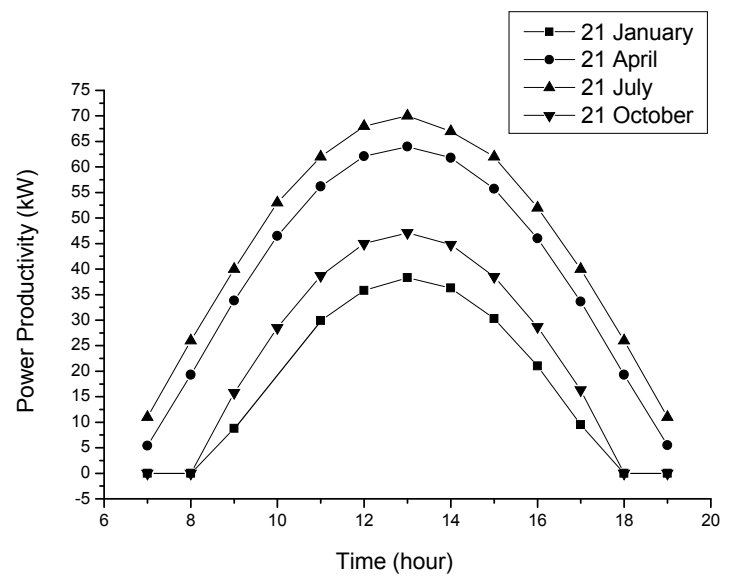

Fig. 11. Variation of power productivity

Figure 11 shows that the production of electrical energy is higher during the periods of spring and summer. This can be explained by the fact that the solar radiation and ambient temperature are higher in spring and summer than in the other two seasons. The production of electrical energy varies respectively as the following:

$\checkmark$ From 5 to $35 \mathrm{~kW}$ during the day of January 21;

$\checkmark$ From 5 to $65 \mathrm{~kW}$ during the day of April 21;

$\checkmark$ From 10 to $72 \mathrm{~kW}$ for the day of July 21 and;

$\checkmark$ From 15 to $47 \mathrm{~kW}$ during the day of October 21 .

\section{Conclusion}

In this work, the influence of solar radiation and ambient temperature on the electrical energy produced by a solar chimney in the region of M'Sila (Algeria) is studied. The results led to the following notes:

- The production of electrical energy is closely related to solar radiation and ambient temperature. Nevertheless, the effect of radiation is much important.
- The trend of the variation of energy production is similar to that of sunlight.

- The efficiency of the turbine has a crucial role in the production of electrical energy.

- The installation of a solar chimney in the region of M'Sila (Algeria) having the same dimensions as the prototype Manzaneres (Spain) will produce $39-72 \mathrm{~kW}$, which will be used to supply electricity to $39000-$ 72000 inhabitants. This will increase the current output of $22 \mathrm{~kW}$ and lead to reduce the cost of $\mathrm{kW}$.

\section{References}

[1] Franz Treib,Ole langnib and Helmu Klaib,"Solar Electricity Generation -A comparative view of Technologie,Costs and Environmental Impact", Solar Energy 59, NOS, 1-3, PP 8999; 1997.

[2] S.V.Patankar "Numerical heat transfer and fluid flow". Hemisphere Publishing Corporation, New York 1980.

[3] Documentation FLUENT: Fluent Inc, July 26,1998

[4] Gannon Aj, Backs TWV. Solar chimney cycle analysis with system loss and solar collector performance. ASME, Journal of Solar Energy engineering.2000.122:133-7

[5] Salah Larbi, Amor Bouhdjar and Toufik Chergui," Performance analysis of a solar chimney power plant in the southwestern region of Algeria", Renewable and Sustainable Energy Reviews 14 (2010) 470-477.

[6] Y.J.Dai, H.B. Huang and R.Z Wang, "Case Study of solar chimney power plants in Northwestern regions of China", Renewable Energy, 28 (2003), pp.1295-1304, October 2002.

[7] Guoliang Xu, Tingzhen Ming, Yuan Pan, Fanlong Meng and Cheng Zhou, "Numerical analysis on the performance of solar chimney power plant system", Energy Conversion and Management 52 (2011) 876-883

[8] Cristiana B. Maia, André G. Ferreira, Ramón M. Valle and Márcio F.B. Cortez, «Theoretical evaluation of the influence of geometric parameters and materials on the behavior of the airflow in a solar chimney", Computers \& Fluids, Article In Press. 